RESEARCH ARTICLE

\title{
Antifungal Susceptibility Pattern among Candida species: An Evaluation of Disc Diffusion and Micro Broth Dilution Method
}

\author{
Abirami Lakshmy Jayachandran ${ }^{1}$, Radhika Katragadda ${ }^{2}$, Thyagarajan Ravinder ${ }^{2}$, Leela Vajravelu ${ }^{2}$, \\ Lavanya Manorajan $^{2}$, S. Hemalatha ${ }^{2}$, Kaliappan Shanmugam ${ }^{3}$ \\ ${ }^{1}$ Department of Microbiology, Karpagavinayaga Institute of Medical Sciences and Research Center, Kanchipuram, \\ Tamil Nadu, India \\ ${ }^{2}$ Department of Microbiology, Government Kilpauk Medical College and Hospital, Chennai, Tamil Nadu, India \\ ${ }^{3}$ Dharmapuri Government Medical College, Tamil Nadu, India
}

\begin{abstract}
Objective: Candida species are emerging as a significant pathogen certain species of Candida like Candida krusei are inherently resistant to azoles. In vitro susceptibility testing is essential for guiding therapy. The present study aims to study the antifungal susceptibility pattern of Candida isolates by disc diffusion and micro broth dilution method and to evaluate the degree of agreement between both the techniques.
\end{abstract}

Methods: Candida isolated from specimens like Oropharyngeal swabs, blood, pus and wound swabs were included in the study. Speciation was done as per standard microbiological methods. Antifungal resistance was determined by disc diffusion method for fluconazole, Itraconazole, amphotericin B, nystatin and clotrimazole. Microbroth dilution method was performed for fluconazole, Itraconazole and amphotericin $B$. The degree of agreement between both the methods for the resistant isolates was analysed by deriving the kappa value.

Results: Out of the 156 Candida isolates obtained, Candida albicans was the most common species isolated. By disc diffusion method fluconazole and Itraconazole showed an overall resistance of $34(21.7 \%)$ and 27 (17.3\%), respectively. Using micro broth dilution method, Fluconazole and Itraconazole had a resistance percentage of 35 $(22.4 \%)$ and $29(18.5 \%)$, respectively. There was a good agreement between both the methods in detecting the percentage of resistant isolates for fluconazole and Itraconazole $(\mathrm{k}=0.9)$.

Conclusion: It is essential to perform susceptibility testing for all the Candida isolates for providing crucial information about the resistance pattern and help in choosing the appropriate antifungal drug for therapy. Disc diffusion method which is easy to perform can be utilized for day to day practice. J Microbiol Infect Dis 2018; 8(3):97101

Keywords: Broth micro dilution, Candida, Disc diffusion

\section{INTRODUCTION}

Candida is present as a normal commensal of the gastrointestinal tract. Candida species have become a significant nosocomial pathogen with raise in drug resistant isolates. Species level identification is essential as certain species like Candida krusei are inherently resistant to azole drugs [1].

Antifungal drug therapies are selected empirically, but in vitro susceptibility testing are essential for guiding or altering the therapy. Fluconazole is the common azole antifungal drug that is being prescribed to immune compromised individuals either as prophylaxis or for therapy [2].

Owing to the rise of drug resistant isolates the study of Antifungal drug resistance remains an area of significant importance [3]. The drug susceptibility testing methods must be precise, cost effective and easily reproducible. In the present study the degree of agreement between two antifungal susceptibility methods, disc diffusion method and Microbroth dilution method for the resistant isolates was analyzed.

Correspondence: Dr. Abirami Lakshmy Jayachandran

Karpagavinayaga Institute of Medical Sciences and Research Center, Madhurantakam, Kanchipuram, Tamil Nadu, India Email: drabi3285@gmail.com

Received: 15 March 2017 Accepted: 19 July 2018

Copyright (C JMID / Journal of Microbiology and Infectious Diseases 2018, All rights reserved 


\section{METHODS}

This cross sectional study was done in the Department of Microbiology, Government Kilpauk medical college, Chennai, India, between June 2012 and December 2012. The study was approved by the institutional ethics committee. A total of 156 Candida spp isolated from various clinical specimens such as oropharyngeal swabs (HIV seropositive patients, diabetics, cancer patients), burns wound infection, diabetic foot ulcer, pus, blood and urine specimens were included in the study (Table 1). All other specimens where isolates other than Candida spp were obtained were excluded from the study. All the 156 isolates were subcultured onto Sabouraud dextrose agar and incubated at $37{ }^{\circ} \mathrm{C}$ for 24 to 48 hours and the growth of creamy white colonies were subjected to gram staining and further speciation was done as per standard Microbiological techniques (germ tube test, colour of the colonies in Chrom agar, morphology in corn meal agar, sugar assimilation test and sugar fermentation tests) [4]. Further antifungal susceptibility testing was performed by disc diffusion method and broth micro dilution method and the degree of agreement between both the methods for the resistant isolates were analyzed.

\section{Antifungal susceptibility testing by disc diffusion method}

Inoculum preparation: The colonies were mixed in $0.85 \%$ sterile normal saline ( $5 \mathrm{ml}$ volume) and adjusted to a turbidity of 0.5 McFarland standards. Meuller Hinton agar with $2 \%$ glucose and $0.5 \mu \mathrm{g} / \mathrm{ml}$ of methylene blue was used.

Procedure: A sterile swab was used to inoculate the plate by making a lawn culture by rotating the plate 180 degree in three directions. The antifungal discs fluconazole $25 \mu \mathrm{g}$, Itraconazole $10 \mu \mathrm{g}$, amphotericin B $100 \mathrm{U}$, clotrimazole $10 \mu \mathrm{g}$ and Nystatin $10 \mu \mathrm{g}$ were placed on the plate and incubated at $37{ }^{\circ} \mathrm{C}$ for $18-24$ hours. The zone sizes were interpreted as per Clinical Laboratory Standards Institute (CLSI) guidelines [5].

\section{Broth Micro dilution method}

Medium used: RPMI (Rosewell park memorial institute medium) 1640 medium with glutamine, without bicarbonate in MOPS (3N-Morpholino propane sulphonic acid).

\section{Inoculum preparation}

The stock suspension was prepared by suspending individual colonies in $5 \mathrm{ml}$ of sterile normal saline ( $0.5 \mathrm{McF}$ arland Standard). The stock suspension was further diluted to $1: 1000$ in RPMI medium (contains $1 \times 103$ to $5 \times 103$ cells $/ \mathrm{ml})$.

\section{Antifungal stock solution}

Sterile distilled water was used to dissolve fluconazole powder and DMSO (dimethyl sulfoxide) was used for dissolving amphotericin $B$ and Itraconazole. The antifungal stock suspension was prepared in the range as follows: fluconazole $64 \mu \mathrm{g} / \mathrm{ml}-0.125 \mu \mathrm{g} / \mathrm{ml}$ and amphotericin B and Itraconazole $16 \mu \mathrm{g}-0.031$ $\mu \mathrm{g} / \mathrm{ml}$.

\section{Procedures}

Disposable 96 well microtitre plates were used. Row 1 had the highest drug concentration and lowest concentration in row 10 . Sterility control and growth controls were also included $100 \mu \mathrm{l}$ of $2 x$ concentration of inoculum was added to each well followed by $100 \mu \mathrm{l}$ of $2 x$ concentration of the drug were added to the corresponding wells (row 1 highest concentration to row 10 lowest concentration). The microtitre plates are incubated at $37{ }^{\circ} \mathrm{C}$ for 24 to 48 hours . The MIC (minimum inhibitory concentration) end point was observed and interpreted as per CLSI guidelines [6].

Candida albicans ATCC 90028 strains was used for quality control.

\section{Statistical Analysis}

The degree of agreement between both the methods for the resistant isolates was analyzed by deriving the kappa value.

\section{RESULTS}

A total of 156 Candida isolates were obtained from various specimens such as oral swabs (HIV positive patients and cancer patients), wound swabs from diabetic patients and burns patients, blood, us ,urine and perianal candidiasis (Table 1). Candida albicans 93 (59.6\%) was the most common species isolated. Among non-albicans Candida, Candida tropicalis $30(19.2 \%)$ was the commonly isolated species (Table 2).

By disc diffusion method fluconazole and Itraconazole showed an overall resistance of 34 
$(21.7 \%)$ and $27 \quad(17.3 \%)$ respectively. Clotrimazole andnystatin showed a resistance of 12 (7.69\%) and 9 (5.76\%) respectively. Amphotericin B showed a lowest resistance of 2 $(1.28 \%)$. Antifungal susceptibility of the individual species is depicted in (Table 3).

Table 1. Distribution of various clinical specimens.

\begin{tabular}{lc}
\hline Specimens & Number \\
\hline Oropharyngeal swabs & \\
$\quad$ HIV seropositive patients & 33 \\
$\quad$ Diabetes mellitus patients & 25 \\
$\quad$ Others (carcinoma patients with oral & 18 \\
$\quad$ lesions, & \\
$\quad$ oral ulcers in denture wearers) & \\
Burns wound swab & 28 \\
Diabetic foot ulcer & 18 \\
Pus samples & 17 \\
Urine & 8 \\
Blood & 6 \\
Perianal samples & 3 \\
Total & 156 \\
\hline
\end{tabular}

By broth micro dilution method, fluconazole and Itraconazole showed a resistance percentage of $35(22.4 \%)$ and $29(18.5 \%)$ respectively (Table 4). Non-albicans Candidas showed a higher resistance compared to Candida albicans by both disc diffusion and broth micro dilution method (Table 3 and 4).

Table 2. Species wise distribution of the Candida isolates.

\begin{tabular}{lc}
\hline Isolate & No. of isolates (\%) \\
\hline Candida albicans & $93(59.6)$ \\
Candida tropicalis & $30(19.2)$ \\
Candida krusei & $11(7.05)$ \\
Candida glabrata & $10(6.41)$ \\
Candida parapsilosis & $9(5.76)$ \\
Candida dubliniensis & $3(1.92)$ \\
Total & $156(100.0)$ \\
\hline
\end{tabular}

The strength of agreement between the disc diffusion method and broth microdilution methods was analyzed and the kappa value was derived. There was a good agreement between both the methods in detecting the percentage of resistant isolates (Table 5).

Table 3. Antifungal drug resistance determined by the disc diffusion method.

\begin{tabular}{lccccc}
\hline Antifungal drug & $\begin{array}{c}\text { Fluconazole, } \mathbf{n} \\
(\%)\end{array}$ & $\begin{array}{c}\text { Itraconazole, } \mathbf{n} \\
(\%)\end{array}$ & $\begin{array}{c}\text { Nystatin, } \mathbf{n} \\
(\%)\end{array}$ & $\begin{array}{c}\text { Clotrimazole, } \mathbf{n} \\
(\%)\end{array}$ & $\begin{array}{c}\text { Amphotericin B, } \mathbf{n} \\
(\%)\end{array}$ \\
\hline $\begin{array}{l}\text { Candida albicans, } \\
n=93\end{array}$ & $11(11.8 \%)$ & $10(10.75 \%)$ & $5(5.37 \%)$ & $7(7.52 \%)$ & $1(1.07 \%)$ \\
$\begin{array}{l}\text { Candida tropicalis, } \\
n=30\end{array}$ & $5(16.66 \%)$ & $7(23.33 \%)$ & $1(3.33 \%)$ & $4(13.33 \%)$ & $1(3.33 \%)$ \\
$\begin{array}{l}\text { Candida krusei, } n=11 \\
\text { Candida glabrata, }\end{array}$ & $11(100 \%)$ & $3(27.2 \%)$ & $3(27.2 \%)$ & $1(9.09 \%)$ & 0 \\
$n=10$ & $7(70 \%)$ & $7(70 \%)$ & 0 & 0 & 0 \\
$\begin{array}{l}\text { Candida parapsilosis, } \\
n=9\end{array}$ & 0 & 0 & 0 & 0 & 0 \\
$\begin{array}{l}\text { Candida dubliniensis, } \\
n=3\end{array}$ & 0 & 0 & 0 & 0 & 0 \\
\hline $\begin{array}{l}\text { Non Candida } \\
\text { albicans }\end{array}$ & $23(36.5 \%)$ & $17(26.9 \%)$ & $9(14.2 \%)$ & $12(19 \%)$ & $1(1.5 \%)$ \\
\hline \begin{tabular}{l} 
Total 156 \\
\hline
\end{tabular} & $34(21.7 \%)$ & $27(17.3 \%)$ & $9(5.76 \%)$ & $12(7.69 \%)$ & $2(1.28 \%)$ \\
\hline
\end{tabular}


Table 4. Antifungal drug resistance pattern observed by Microbroth dilution method.

\begin{tabular}{llllll}
\hline \multirow{2}{*}{ Antifungal drug } & \multicolumn{2}{l}{ Fluconazole } & \multicolumn{2}{l}{ Itraconazole } & \multirow{2}{*}{ Amphotericin B } \\
& $\mathbf{n}(\%)$ & $\mathbf{S D D}$ & $\mathbf{n}(\%)$ & SDD & \\
\hline Candida albicans, $\mathrm{n}=93$ & $10(12.9)$ & $2(2.1)$ & $11(11.8)$ & $4(4.3)$ & $1(1.07)$ \\
Candida tropicalis, $\mathrm{n}=30$ & $8(26.6)$ & $1(3.33)$ & $7(23.3 \%)$ & $1(3.33)$ & 0 \\
Candida krusei, $\mathrm{n}=11$ & $11(100)$ & 0 & $4(36.3)$ & 0 & 0 \\
Candida glabrata, $\mathrm{n}=10$ & $6(60)$ & 0 & $7(70)$ & 0 & 0 \\
Candida parapsilosis, $\mathrm{n}=9$ & 0 & 0 & 0 & 0 & 0 \\
Candida dubliniensis, $\mathrm{n}=3$ & 0 & 0 & 0 & 0 & 0 \\
Non Candida albicans & $24(39.6)$ & 0 & $18(28.5)$ & 0 & 0 \\
\hline Total 156 & $35(22.4)$ & $3(1.9)$ & $29(18.5)$ & $5(3.2)$ & $1(1.07)$ \\
\hline
\end{tabular}

Table 5. Agreement between disc diffusion method and Microbroth dilution method in the identification of resistant isolates.

\begin{tabular}{lccc}
\hline $\begin{array}{l}\text { Strains } \\
\text { No }\end{array}$ & $\begin{array}{c}\text { Antifungal } \\
\text { drug }\end{array}$ & $\begin{array}{c}\text { Kappa } \\
\text { value }\end{array}$ & $\begin{array}{c}\text { Strength of } \\
\text { agreement }\end{array}$ \\
\hline 1 & Fluconazole & 0.981 & Very good \\
2 & Itraconazole & 0.936 & Very good \\
3 & $\begin{array}{c}\text { Amphotericin } \\
\text { B }\end{array}$ & 0.316 & Good \\
\hline
\end{tabular}

\section{DISCUSSION}

Because of the increasing incidence of Candida infection along with the emergence of drug resistant phenotypes, it is essential to provide the clinicians with the antifungal susceptibility pattern for better treatment outcomes. Various guidelines such as CLSI, European Committee on Antimicrobial Susceptibility Testing have proposed reference methods for performing and interpreting antifungal susceptibility tests.

Candida albicans was the predominant species isolated followed by Candida tropicalis similar to other studies in literature [7-9]. By disc diffusion method, fluconazole and Itraconazole showed a resistance of $21.7 \%$ and $17.3 \%$ respectively. Among the Candida isolates resistance percentage of 12 to $34 \%$ for fluconazole have been documented [3,10-12]. Clotrimazole showed a resistance percentage of $7.6 \%$. Candida albicans showed a resistance of $11.8 \%$ for fluconazole similar to Jayalakshmi et al. [12]. Candida krusei and Candida glabrata showed a resistance of $100 \%$ and $70 \%$ respectively. By broth micro dilution method, the overall fluconazole resistance was $22.4 \%$ similar to Adhikary et al. (25\%) [13]. Itraconazole showed a resistance percentage of $18.5 \%$. Rex et al has reported Itraconazole resistance as 25\% [13]. Amphotericin $B$ showed a resistance percentage of $1.2 \%$. Khotari et al has reported a resistance of $8 \%$ for amphotericin B [14]. The advent of antifungal drug resistance and isolation of Nonalbicans Candida with inherent drug resistance can be attributed to the indiscriminate usage of antifungal drugs, immunocompromised states like HIV and cancer chemotherapy requiring prophylactic and empiric antifungal therapy [15]. Shift in the spectrum of infection from Candida albicans to non-albicans Candidas can impose difficulties in controlling the infections.

In the present study there was a good agreement between the disc diffusion method and broth micro dilution method in identifying the drug resistant isolates for fluconazole and Itraconazole (kappa value 0.9) similar some previous studies $[11,16,17]$.

Disc diffusion method is easy to perform and can be interpreted by 24 hours and can be used for diagnostic purposes on daily basis whereas broth micro dilution method is cumbrous as it requires more practical skills. Disc diffusion 
method which is easy to perform can be utilized for day to day practice. It is essential to perform susceptibility testing for all the Candida isolates for providing crucial information about the resistance pattern and help in choosing the appropriate antifungal drug for therapy. Periodic antifungal resistance surveillance protocols must be formulated for studying the trend of antifungal resistance in a particular area. This also will guide in choosing the empiric/prophylactic drug before the antifungal resistance pattern is available.

\section{ACKNOWLEDGMENTS}

Declaration of Conflicting Interests: The authors declare that they have no conflict of interest.

Financial Disclosure: No financial support was received.

\section{REFERENCES}

1. Gill K, Kumar S, Xess I, Dey S. Novel synthetic anti-fungal tripeptide effective against Candida krusei. Indian J Med Microbiol 2015; 33 (1):110116.

2. Jayachandran AL, Katragadda R, Thyagarajan R, et al. Oral Candidiasis among Cancer Patients Attending a Tertiary Care Hospital in Chennai, South India: An Evaluation of Clinic mycological Association and Antifungal Susceptibility Pattern. Can J Infect Dis Med Microbiol 2016; 8758461. http://dx.doi.org/10.1155/2016/8758461

3. Giri S, Kindo AJ. Evaluation of Antifungal susceptibility testing in Candida isolates by Candifast and disk-diffusion method. Indian J Pathol Microbiol 2014; 57:595-7.

4.Agarwal S, Manchanda V, Verma N et al. Yeast identification in routine clinical microbiology laboratory and its clinical relevance. Indian J Med Microbiol.2011; 29 (2): 172-177.

5. Clinical and Laboratory Standards Institute. Method for antifungal disk diffusion susceptibility testing of yeasts; approved guideline, $2^{\text {nd }}$ ed., M44A2.Clinical and Laboratory Standards Institute, Wayne, PA.USA 2008.

6 .Clinical and Laboratory Standards Institute (CLSI), "Reference method for broth dilution antifungal susceptibility testing of yeasts. $3^{\text {rd }}$ ed., Document M27-A3, Wayne, Pa, USA, 2008.

7. Tankhiwale S, Gajbhiye S, Powar R. fluconazole susceptibility testing of Candida species by disc diffusion and agar dilution method. J Evolut Med Dent Sci 2012; 1(4): 527-531.

8 .Ying Y, Zhang J, Huang SB et al. Fluconazole susceptibility of 3,056 clinical isolates of Candida species from 2005 to 2009 in a tertiary-care hospital. Indian J Med Microbiol 2015; 33(3):413415.

9. Pfaller MA, Diekema DJ, Gibbs DL et al. Global Antifungal Surveillance Group Results from the ARTEMIS DISK Global Antifungal Surveillance Study, 1997 to 2007: A 10.5-year analysis of susceptibilities of Candida species to fluconazole and voriconazole as determined by CLSI standardized disk diffusion. J Clin Microbiol 2010; 48 (4):1366-77.

10. Gandhi TN, Patel MG, Jain MR. Antifungal Susceptibility of Candida against Six Antifungal Drugs by Disk Diffusion Method Isolated from Vulvovaginal Candidiasis. Int J Cur Res Rev 2015; 7 (11): 20-25.

11. Kumar D, Bhattacharyya S, Gupta $P$, et al. Comparative Analysis of Disc Diffusion and E-test with Broth Micro-dilution for Susceptibility Testing of Clinical Candida Isolates Against Amphotericin $\mathrm{B}$, Fluconazole, Voriconazole and Caspofungin. J Clin Diag Res 2015; 9 (11): 1-4.

12.Jayalakshmi L, Ratna Kumari G, Samson SH. Isolation, Speciation and Antifungal Susceptibility Testing of Candida from Clinical Specimens at a Tertiary Care Hospital. Sch J App Med Sci, 2014; 2(6E):3193-198.

13.Adhikary R, Joshi S. Species distribution and antifungal susceptibility of candidemia at a multi super specialty centre in Southern India. Indian J Med Microbiol 2011; 29(3):309-311.

14.Rex JH, Rinaldi MG, Pfaller MA. Resistance of Candida species to fluconazole. Antimicrob Agents Chemother 1995; 39(1): 1-8.

15. Kothari A, Sagar V. Epidemiology of candida blood stream infections in a tertiary care institute in India. Indian J Med Microbiol 2008; 27(2):171-172.

16. Matar MJ, Zeichner LO, Paetznick VL, et al. Correlation between E-Test, Disk Diffusion, and Microdilution Methods for Antifungal Susceptibility Testing of Fluconazole and Voriconazole. Antimicrob Agents Chemother. 2003; 47(5): 16471651.

17. Negri $\mathrm{M}$, Henrique's $\mathrm{M}$, Svidzinski $\mathrm{TI}$, et al. Correlation between $\mathrm{E}$ test, disk diffusion, and microdilution methods for antifungal susceptibility testing of Candida species from infection and colonization. J Clin Lab Anal 2009; 23(5): 324-330. 